\title{
Confusion and Path of Preschool Teachers' Professional Development under the Background of Big Data
}

\author{
Yuan Qiu \\ College of Education Science, Gannan Normal University, Ganzhou, China \\ Email: 13824577584@163.com
}

How to cite this paper: Qiu, Y. (2019) Confusion and Path of Preschool Teachers' Professional Development under the Background of Big Data. Open Access Library Journal, 6: e5836.

https://doi.org/10.4236/oalib.1105836

Received: October 8, 2019

Accepted: October 18, 2019

Published: October 21, 2019

Copyright $\odot 2019$ by author(s) and Open Access Library Inc.

This work is licensed under the Creative Commons Attribution International License (CC BY 4.0).

http://creativecommons.org/licenses/by/4.0/ (c) (i) Open Access

\begin{abstract}
The advent of "Big Data" has brought a new round of challenges to the professional development of preschool teachers in China. At the same time, it has also put forward new requirements for the professional development of preschool teachers. Based on the perspective of big data, this paper proposes the path of professional development of preschool teachers in the context of big data by analyzing the confusion faced by the professional development of preschool teachers in the context of big data. The first is to change the traditional concept and reshape the role of preschool teachers. The second is to transform the teaching thinking and change the teaching methods of preschool teachers. The third is to update the development model so that the professional development model of preschool teachers can keep pace with the times. The ultimate goal is to enable preschool teachers to better improve their professional development skills.
\end{abstract}

\section{Subject Areas}

Education

\section{Keywords}

Big Data, Preschool Teachers, Professional Development

\section{Introduction}

With the development and progress of the Times, in many industries, "Big Data" has attracted more and more attention, especially in the education industry. As an indispensable and important part of kindergarten education and teaching, preschool teachers have encountered many difficulties and perplexities in their 
professional development with the advent of the age of big data. Due to the professionalism and particularity of preschool teachers, where should preschool teachers' professional development go in the context of big data has attracted the great importance of experts in the education field. Under the background of big data, the role of preschool teachers and their own development model are facing new challenges. How to explore a new path that is conducive to the professional development of preschool teachers is an important issue that preschool educators must think about.

\section{Basic Overview of "Big Data"}

\subsection{Definition of "Big Data"}

In recent years, due to the rapid development and dissemination of information technology such as computers and Internet of Things, big data has become the hottest and most popular word in the world and has become a new hot spot in the world. Big data has opened a major era transformation, and the information storm brought by it is transforming our life, work and thinking.

A pioneer in the study of big data-the world's most famous management consulting firm: McKinsey \& Company has defined "Big Data" in the early years: Big Data refers to data set that exceeds conventional database tool acquisition, storage, management, and analysis capabilities [1]. It is worth mentioning that it also emphasizes that data sets that do not necessarily exceed a certain TB value can be counted as big data. For another instance, Wikipedia, a collaborative project for a global multilingual encyclopedia based on wiki technology, defines

"Big Data" as huge amounts of data or the big data. It refers to the amount of data involved that is too large to be captured, managed, processed and collated in a reasonable amount of time by current mainstream software tools to help enterprises make more active business decisions. Moreover, International Data Corporation (IDC) defines "Big Data" as: Big Data technology describes a new generation of technology and architecture, which is used to capture, discover and analyze technologies in a very economical way and at a high speed to extract value from various super-large Data [2].

In fact, experts give different definitions of "Big data", and there is no unified definition. As the saying goes, "Different people have different opinions". However, what they all generally agree on is that big data has changed from the early definition of "3Vs" and " $4 \mathrm{Vs}$ " to the current definition of "5Vs", namely Volume, Velocity, Variety, Veracity and Value [3].

\subsection{Basic Characteristics of "Big Data"}

In fact, the above definition of " $5 \mathrm{Vs}$ " for big data contains five basic characteristics of big data, which mainly includes the following meanings: 1) In terms of quantity, the data volume is huge, that is, the data capacity and scale are huge, and it is difficult to measure the huge amount of data. 2) From the perspective of speed, the speed of data analysis and collation is extremely fast, with high speed 
and timeliness. It can provide a large amount of data information in a very short time and the growth rate is extremely fast. When it comes to data processing, there is a famous "One-second Rule", which means that the analysis results should be given within the time range of seconds, beyond which the data will lose its value. 3) In terms of types, the sources and types of data are diverse, and the data formats are increasingly diversified. Its data types are various, including not only traditional formatted data, but also web logs, video, audio, pictures, geographic information and other types of data from the Internet. 4) From the perspective of authenticity, it refers to the pursuit of high-quality data, whose source is complete and true and inseparable from our daily life. 5) From the perspective of value, data is of high value. In other words, the core of big data is to gain insight and value. By analyzing and sorting out a large amount of data information, we can obtain higher value [4].

Since then, although different scholars and research institutions have given different definitions of big data, most of them mention the five basic characteristics mentioned above, such as " $4 \mathrm{~V}+\mathrm{C}$ " characteristics-Volume (large amount of data), Variety and Value (low Value density), Velocity and Complexity; And like a "11V" features-Volume, Variety, Velocity, Value, Veracity, Visualization, Validity, Variability, Viability, Volatility, Visibility and so on.

\subsection{Application of "Big Data"}

At present, big data is quietly changing our daily life. With the rapid development of the Internet, the application of big data is more and more extensive, in all walks of life have been widely used. For example, online education service platform KNEWTON, a start-up company that provides personalized education, can adapt to the personalized needs of each learner, analyze the advantages and disadvantages of each student according to the data, and give each student effective guidance. Another example is TXU Energy smart electricity meter, a case of big data application in the Energy industry. It can read electricity consumption data every 15 minutes, thus saving labor and time. It can also predict customers' electricity consumption habits and work out different electricity prices. There are also big data application cases in medical and health care-Baidu inc. disease forecast products, to a variety of diseases such as influenza, hepatitis, tuberculosis, venereal disease outbreak prediction and health, it is the use of big data analysis route to predict flu, that is, it can be based on people's search and shopping behavior, and predict the possibility of a large outbreak, if the flu from a particular region, radix is a tidis search demand more and more, through analyzing the huge data in real time, then we can infer the area has a tendency to outbreak of influenza. In addition, big data is also widely used in urban management, government field, security field, catering, automobile, telecommunications and other industries. Although the application scope of big data is becoming more and more extensive, it is undeniable that the current application of big data is still just the tip of the iceberg, waiting for people to continue to explore and develop. 


\section{Confusion of Preschool Teachers' Professional Development under the Background of Big Data}

\subsection{Redefining the Role of Preschool Teachers}

In the traditional kindergarten classroom, the preschool teachers bear the dual functions of childcare and education, which is related to the healthy growth of hundreds of millions of children and the healthy development of preschool educational undertaking [5]. Preschool teacher not only an imparter who help young children acquire knowledge, an expositor who help young children face confusion, but also a guider when children playing games, a designer of children practical activity, what is more the preschool teacher is the arranger and leader of the child's daily life.

But with the advent of the era of big data, the way children acquire knowledge is no longer limited to kindergartens, and they no longer rely on teachers in traditional education. Because in addition to kindergarten, young children can learn through other platforms. Such as: China's largest kindergarten alliance home education portal—China Early Childhood Education Online, its " $\mathrm{Da} \mathrm{Ai}$ Wuer" as its website concept, is a comprehensive service website for the purpose of serving kindergartens, parents and children. Another example: early childhood education application APP_Children's Enlightenment, Children's Audio Fairy Tales, I Love Chinese Characters, Children's Songs Duoduo and so on. Another example: VIPKID Online Children's English, taking a one-to-one personalized teaching form of foreign teachers in North America, breaking the traditional one-to-many teaching form and other learning ways to gain knowledge.

Therefore, in the new era in which big data continues to promote the development of educational informatization, the traditional role of preschool teachers is obviously difficult to adapt to the rhythm of the development of the times. It is necessary to change the traditional educational concept and reshape the role of preschool teachers.

\subsection{Challenges Faced by Preschool Teachers' Teaching Methods}

The traditional teaching concepts and ideals believe that teacher's teaching should focus on teaching materials, that is, teachers follow the teaching materials, the classroom follows the teaching plan, the students follow the teachers, and everything follows the rules and step-by-step. Leading to the traditional teaching classroom is a classroom with "teacher as the main body and students as the object". It adopts the teaching methods of "cramming", "full house irrigation", "teacher speaking, student listening" and "indoctrination". However, with the advent of the era of big data, teachers are no longer advocated to follow the teaching materials, students follow the teachers, but require teachers to develop a personalized teaching method that is truly suitable for students to learn and absorb. At the same time, students are required to have a personalized way of learning and be subjective initiative, can treat things with their own unique views and ideas, rather than follow the teacher completely. 
In fact, with the rapid development of information technology, people have long realized that the traditional teaching method is obviously not the best way of teaching at present, and the emergence of "multimedia" temporarily eases the status quo. There has been a hybrid teaching method combining multimedia teaching or multiple teaching methods have emerged [6]. Preschool teachers have shifted from traditional teaching methods to multimedia teaching, allowing advanced multimedia equipment to enter traditional classrooms, so that the teaching methods of preschool teachers are no longer limited to traditional teaching methods, which means that preschool teachers must have certain modern information technology knowledge [7]. This is also one of the general knowledge that preschool teachers must have in "Professional Standards for Kindergarten Teachers (Trial)" (hereinafter referred to as "Professional Standards"). At the same time, it also means that preschool teachers must constantly improve their information technology skills in order to better face the challenges brought by big data to traditional teaching methods and keep pace with the progress of the times.

\subsection{Re-Recognition of Preschool Teachers' Self-Development Model}

Generally speaking, the preschool teachers' own development model is more common in the following two modes: one is the kindergarten-based training mode; the other is the expert lecture mode [8]. Kindergarten-based training model is a form of organizational learning within kindergartens themselves. With the help of kindergarten-based training, kindergarten teachers can communicate and learn from each other, and learn from others' strong points to offset one's weakness, but their disadvantages are obvious. That is to say, there is little communication with outside preschool teachers, and the object of learning from each other is only limited to the kindergarten. In the long run, it is difficult for preschool teachers to make a breakthrough in their professional development, which is not conducive to the professional development of preschool teachers. The expert lecture mode refers to inviting experts who are related to early childhood education or related to a certain field of education to hold lectures on the prevailing situation of preschool teachers. It is undeniable that this mode is conducive to the development of preschool teachers themselves, and can play a certain role in guiding and promoting preschool teachers' professional development. However, due to the short time of expert lecture mode and the strong theoretical nature of the content spoken by the expert, it is difficult for preschool teachers to absorb and digest it in a short time and then transform it into their own, which is not conducive to the individualized development of preschool teachers, and is also not conducive to the development of preschool teachers themselves.

Therefore, with the rapid development of The Times and the increasing diversification of learning approaches, preschool teachers must keep up with the pace of The Times, constantly update their own development model, make full preparations for the arrival of the era of "Big Data", and become excellent people's 
teachers who are reused by leaders, trusted by parents and loved by students.

\section{Path of Preschool Teachers' Professional Development under the Background of Big Data}

\subsection{Changing Traditional Ideas and Reshaping the Role of Preschool Teachers}

Faced with the rapid development of information age, children's learning channels no longer only rely on kindergarten teachers, the traditional role of preschool teachers has been difficult to meet the needs of children. "Professional Standards" clearly indicate that preschool teachers who should identity the professionalism and uniqueness of preschool teachers [7]. "Guidelines for the Guidance of Kindergarten Education (Trial)" advocated that preschool teachers should become supporters, guiders and cooperators of children learning activities [9]. Therefore, in line with the consciousness of keeping pace with the times and changing traditional concepts, preschool teachers no longer play the traditional role of teachers, but with the progress of the times, the role of preschool teachers has changed, and the role of preschool teachers has been reshaped. Under the background of big data, the role of teachers has changed from traditional classroom instructor to modern classroom guide, from expositor who help young children face confusion to enlightener, from leader when children playing games to participator, from designer of children's practical activities to collaborator and so on.

There is a saying in the old saying: "It is better to teach a man how to fish than to give him the fish." The remolding of preschool teachers' role is aimed at requiring preschool teachers to change the traditional concept in time, so as to better adapt to the transformation of preschool teachers' role from the traditional role to the diversified role of preschool teachers in the new era. It also shows that under the background of big data, preschool teachers must change their traditional ideas and refresh their educational concept, so as to truly keep pace with The Times and better adapt to the diversification of the role of preschool teachers under the background of big data.

\subsection{Transforming Teaching Thinking and Changing Preschool Teachers' Teaching Ways}

The Times are developing, so are teachers. The era of development must have teachers who can develop, the era of innovation must have innovative teaching methods, and to have innovative teaching methods requires teachers to have innovative thinking. On October 26, 2017, the Ministry of Education of the People's Republic of China promulgated "Standards for Accreditation of Preschool Education Specialty", which clearly stipulates that as a qualified professional preschool teachers, they must have a certain sense of innovation, use critical thinking methods, and learn to analyze and solve problems [10]. Education in the context of big data is endowed with boundless lofty and difficult missions 
and responsibilities [11]. At the same time, as an educational staff, they must keep pace with the times and constantly receive the latest educational information. In summarizing the previous educational experience, they should constantly reflect on it and in the existing teaching experience can continue to innovate to form teaching methods with their own educational characteristics. Peers should learn from others' strong points to offset one's weakness, and become a learning community of mutual assistance and complementarity. As preschool teachers in the era of big data, they must have big data thinking to meet the education in the era of big data in the best state.

"Professional Standards" clearly shows that preschool teachers need to master the characteristics and laws of physical and mental development of children of different ages, as well as strategies and methods to promote the comprehensive development of children; to understand the individual differences in the development level, speed, advantages and other aspects of children, and to master the corresponding strategies and methods [7]. Therefore, preschool teachers must break away from the shackle of traditional teaching thinking, carry out personalized teaching according to the physical and mental development characteristics of children at different stages, and realize individualized education as far as possible under the existing conditions, so as to better meet the personalized needs of children, and thus contribute to the overall development of children.

\subsection{Renewing the Development Model to Keep the Professional Development Model of Preschool Teachers up with the Times}

First of all, we must first make clear what is the "professional development of teachers"? After consulting relevant information, it is found that the definition of the concept of "professional development of teachers" involves many concepts such as "teacher professional development", "teacher professional growth" and "teacher specialization" as far as the existing research results are concerned. Different scholars have different definitions of concepts from different dimensions. It can be said that different people have different opinions. Teacher professional development is the process of teachers' self-improvement and self-development, the process of teachers' continuous absorption of new knowledge and enhancement of professional competence; it refers to the process of teachers' self-renewal, development and progress as professional educators in various aspects such as "Cognition, Emotion, Will, Behavior", that is, the process from an immature novice teacher to an expert teacher; it is a dynamic process of development and progress from the initial "non-specialization" to "specialization" and then to "professionalization" [12]. Therefore, the preschool teacher professional development in this study focuses on the process of preschool teachers keeping pace with the times, constantly enriching and improving themselves, constantly meeting the requirements from society, schools, students and parents, and realizing their ideal value in life.

The advent of the era of big data has brought about the rapid development of digital information technology. It is difficult to adapt to the pace of the big data 
era by the traditional professional development model of preschool teachers. As early as the State Council of the People's Republic of China has already clearly pointed out in "Opinions on Strengthening the Construction of Teachers" that it is necessary to promote the deep combination of information technology and teacher education, build teachers' network research community and lifelong learning support service system, promote teachers' independent learning and promote the reform of teaching methods [13]. Therefore, we must update the traditional development model in time, and add new development model on the basis of the original traditional model, so that the professional development model of preschool teachers can keep up with the pace of big data, and then truly keep pace with The Times. At present, Online Teacher's Professional Development (OTPD), as a network learning model different from the traditional teaching model, has broken through the traditional model of teacher professional development to a large extent [8], and has received high attention from many researchers. The arrival of "OTPD model" is conducive to the establishment of online alliance cooperative development model for preschool teachers through the online learning platform [8], forming an online learning community and jointly promoting the professional development of preschool teachers. "OTPD mode" can supervise and motivate each other to a certain extent through the style of online group cooperation, which is conducive to the professional development of preschool teachers. Confucius said, "In the company of three, there must be my teacher". Through the study of the network platform, not only can we improve the level of self-knowledge, broaden the depth and breadth of knowledge, but also learn from their different strengths by contacting different types of teachers, and make up for their own deficiencies, and then through reflection and research, explore A teaching method that suits one's own characteristics.

\section{Conclusion}

With the advent of the era of big data, the professional development of preschool teachers under the background of big data is a persistent endurance battle. In this process, a group of preschool teachers conforming to the trend of The Times are urgently needed. Only by breaking the shackles of traditional education and teaching methods and keeping up with the pace of the development of the Times can we not be eliminated by the Times. Therefore, preschool teachers should keep pace with the Times, change their ideas in time, reshape their roles, change their teaching thinking, update their professional development model, constantly improve their professional development ability, make their professional development ability to a higher level, and then adapt to the pace of the era of big data in the best state.

\section{Acknowledgements}

This research was supported by Research Achievements of the Graduate Innova- 
tion Fund Project of Gannan Normal University in Jiangxi Province, China (2018) "Empirical Study on the Influence of Teachers' Autonomous Support and Family Education on Children's Learning Quality" (Project No. YCX18A010).

\section{Conflicts of Interest}

The author declares no conflicts of interest regarding the publication of this paper.

\section{References}

[1] Li, X.L. and Gong, H.G. (2015) Overview of Big Data Systems. Science China (Information Sciences), 1, 1-44. http://www.cnki.com.cn/Article/CJFDTotal-PZKX201501001.htm

[2] Liu, Z.H. and Zhang, Q.L. (2014) Research Overview of Big Data Technology. Journal of Zhejiang University (Engineering Science), 6, 957-972. http://qikan.cqvip.com/Qikan/Article/Detail?id=50312619\&from=Qikan_Search In $\underline{\mathrm{dex}}$

[3] Fang, W., Zheng, Y. and Xu, J. (2014) Big Data: Conceptions, Key Technologies and Application. Journal of Nanjing University of Information Science \& Technology (Natural Science Edition), 5, 405-419.

[4] Li, W. and Feng, Y.Y. (2016) Thinking of Private College Young Teachers' Professional Development in Big Data Era Background. The Guide of Science \& Education, 3, 56-57.

[5] The Ministry of Education of the People's Republic of China, Central Editorial Office, Ministry of Finance, Ministry of Human Resources and Social Security (2012) Opinions on Strengthening the Construction of Kindergarten Teachers.

http://www.moe.gov.cn/srcsite/A10/s3735/201211/t20121108 145541.html

[6] Jiang, Y. (2016) Analysis on the Professional Development of English Teachers in Higher Vocational Colleges in the Age of Big Data. Overseas English, 9, 35-37. http://www.cnki.com.cn/Article/CJFDTOTAL-HWYY201609019.htm

[7] The Ministry of Education of the People's Republic of China (2012) Circular on the Issuance of "Kindergarten Teachers' Professional Standards (Trial Implementation)”. http://www.moe.gov.cn/srcsite/A10/s6991/201209/t20120913 145603.html

[8] Kang, W.W. (2016) Professional Development of College Teachers in the Era of Big Data. Education and Vocation, 15, 46-47.

[9] Shen, J.Z. (2015) Professional Development of Kindergarten Teachers. 1st Edition, Beijing Normal University Press, Beijing, 18.

[10] The Ministry of Education of the People's Republic of China (2017) Circular on the Issuance of "Implementation Measures for Certification of Teachers' Specialty in General Colleges and Universities (Interim)". http://www.moe.gov.cn/srcsite/A10/s7011/201711/t20171106 318535.html

[11] Fei, Z.D. and Liu, S.R. (2017) The Strategy Research of Teacher's Professional Development under the Horizon of "Big Data”. Journal of Educational Institute of Jilin Province, 7, 36-38.

[12] Cui, Y.X. (2013) Research on the Generating Mechanism of Teachers' Professional Development Motivation in Primary and Secondary Schools. Master's Thesis, Southwest University, Chongqing, China. http://cdmd.cnki.com.cn/Article/CDMD-10635-1013265215.htm 
[13] State Council of the People's Republic of China (2012) Opinions on Strengthening the Construction of Teachers.

http://www.moe.gov.cn/jyb xxgk/moe 1777/moe 1778/201209/t20120907 141772. $\underline{\mathrm{html}}$ 